\title{
A non-linear control strategy for a PV conversion system with energy storage
}

\author{
Ghizlane Traiki. ${ }^{1 *}$, Abdelmounime El Magri ${ }^{1}$, Rachid Lajouad ${ }^{1}$ and Omar Bouattane ${ }^{1}$ \\ ${ }^{1}$ SSDIA Laboratory, ENSET Mohammedia, Hassan II University of Casablanca, BP 159 Bd Hassan II, Mohammedia, Morocco
}

\begin{abstract}
A nonlinear control of a PV Energy Conversion System (PVECS) with energy storage system and maximum power extraction is presented. The control strategy is designed in two steps. Firstly, a MPPT algorithm is designed to tracking the maximum power point in variable irradiations, battery state of charge (SOC) and load changes. Then, thanks to its many advantages such as simplicity against parameter uncertainties, a Sliding Mode Control approach (SMC) is applied to control the standalone PV energy conversion system. Finally, the performances of MPPT techniques and SMC controller in the closed loop are checked using the MATLAB/SIMULINK.
\end{abstract}

Keywords - Solar PV; Sliding Mode Control; MPPT; DC/DC converter, Battery State Of Charge.

\section{Introduction}

In most applications, DC-DC converters are controlled by a voltage mode controller or a current-mode controller. These converters are used in several fields including telephony, electric vehicles and thus smart grids, they are now widely used for renewable energy sources as switching regulator [1-2]. Due to their switching property included in the structure of DC-DC converters, the latter are characterized by their nonlinear properties and their control design complexity. Despite these nonlinear properties, the system can be approximated by a linear system, exploiting the mean method and using linear control methods. The Buck Converter is a ubiquitous converter that is used in many applications. The Buck is characterized by its nonlinear behaviour given its switched state [3-4]. In general, this converter is a single-pole primary inductance converter, which considered as a crucial input inductance, it can be applied for applications wide range with continuous conduction mode (CCM) requirements. It has many advantages by having a control switch connected to the ground. It has also an important role in achieving the application's requirements, it requires the controller domain to be flexible thus drives the quality of control to a high level [5-6] [24, 25, 26].

Furthermore, regulation of the duty cycle allows modifying the input impedance of the converter. The DC-DC converter is characterized by generating a wide range of non-inverted output voltage, which is advantageous for the rising and falling power. The buck is a converter that provides adequate functionality for voltage or current applications as controlled sources [78]. In addition, the buck converter is characterized by its complicity of control, due to its modelling as a nonlinear system [9]. To remedy this complexity, the choice of the controller must meet the following criteria: it must be characterized by the speed of its dynamic response and in addition, it must be stable and robust to the uncertainties of the parameters.

To control the buck converter, several techniques of nonlinear control have been studied such as sliding mode control (SMC). This approach is robust to the variations of parameters; it has a fast dynamic response. The sliding mode control is used to manage the nonlinear system. Despite his criteria, the SMC is limited due to the steady-state error, which figures out in the regulation. This approach is applied in many fields such as DC motors, electrics drives and in automotive [10-16].

In the present paper, a nonlinear controller is developed using variable optimal $\mathrm{PV}$ voltage reference generator. A MPPT regulator is designed using the Sliding Mode Control technique. It is shown that the SMC ensures global asymptotic stability of the closed-loop system and enforces the PV voltage to perfectly track its varying reference trajectory given by the Power to Voltage Optimizer (PVO) developed in [20], despite the changing of the solar irradiations, the battery state of charge and load charge. These performances are also illustrated through simulations.

This paper is presented as follows: Section 2 describes the system and the mathematical model (PV and buck

* Corresponding author: traiki.ghizlane@gmail.com 
converter modelling). The nonlinear sliding mode control is designed and analysed in Section 3. The simulation results and discussions are presented in Section 4. A conclusion and reference list end the paper.

\section{Conversion system modelling}

\subsection{PV panel modelling}

Solar cells mainly contained semiconductors that convert solar energy to electrical power based on the photovoltaic effect. The figure below shows the solar cell equivalent circuit, which comprises a source in parallel with a single-diode.

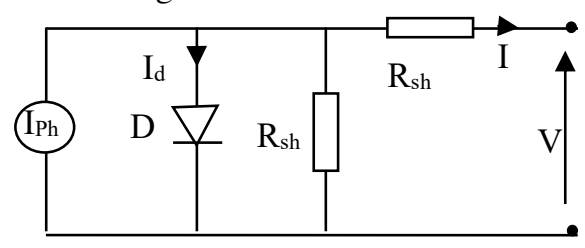

Fig. 1. Equivalent electrical model of the simple junction photovoltaic

Based on the Kirchoff law, the output current the model represented in Fig. $1\left(R_{s}=0\right.$ and $\left.R_{s h}=\infty\right)$ is:

$$
I=I_{d}-I_{p h}
$$

The above equation includes:

$$
\begin{aligned}
& I_{d}=I_{0}\left[\exp \left(\frac{V}{n V_{T}}\right)-1\right] \\
& V_{T}=\frac{K T}{q} \\
& I_{0}=I_{0 r}\left(\frac{T}{T_{r}}\right)^{3} \exp \left[\frac{T}{T_{r}}-1\right] \frac{E_{g}}{n V_{t}} \\
& I_{p h}=\left[I_{s c}+K_{i}(T-298)\right] \frac{E}{1000}
\end{aligned}
$$

Where

$I_{p h}$ : photocurrent.

$I_{d}:$ diode current.

$n$ : diode ideality factor.

$V_{T}$ : thermal voltage.

$K$ : Boltzmann's constant $\left(K=1.3810^{-23} \mathrm{~J} / K\right)$.

$q$ : electron charge $\left(q=1.610^{-19} \mathrm{C}\right)$.

$T$ : temperature of junction.

$I_{0}$ : reverse saturation current of the diode.

$T_{r}$ : nominal temperature.

$E_{g}$ : band gap energy of the semiconductor.

$I_{s c}$ : short circuit current at $298.15^{\circ} \mathrm{K}$.

$K_{i}$ : short circuit current temperature coefficient $\left(K_{i}=0.0017 \mathrm{~A} /{ }^{\circ} \mathrm{C}\right)$.

$E$ : solar radiation $\left(\mathrm{W} / \mathrm{m}^{2}\right)$.

\subsection{Battery modeling}

The equivalent electrical model of the battery includes, at a specific state of charge, an ideal battery voltage v1, the cell Ohmic behaviour which is represented by the equivalent series resistance $r_{c}$, the dynamic response during the charge and discharge regime that is describing by the equivalent circuit $\left(\mathrm{r}_{\mathrm{b}}, \mathrm{C}_{\mathrm{b}}\right)$.

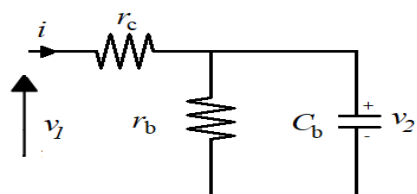

Fig. 2. The battery equivalent circuit

\subsection{DC/DC modelling}

The Fig. 3 represents the studied system, which constitutes a solar panel, a buck converter, the battery energy storage and the load.

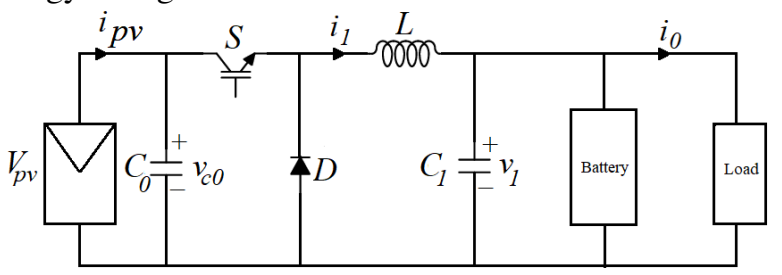

Fig. 3. Electrical circuit of the system

The state-space modeling of the buck converter is obtained from the dynamic equations in the two cases: switch state is ON or OFF. Then the known average technique will be used. The following state space equations describe the average model of buck converter that is obtained from the DC/DC modelling [18]:

$$
\begin{aligned}
& \dot{x}_{1}=\frac{i_{p v}}{C_{0}}-\mu \frac{x_{2}}{C_{0}} \\
& \dot{x}_{2}=\mu \frac{x_{1}}{L}-\frac{x_{3}}{L} \\
& \dot{x}_{3}=\frac{x_{2}}{C_{1}}-\frac{x_{3}}{r_{c} C_{1}}+\frac{x_{4}}{r_{c} C_{1}}-\frac{i_{0}}{C_{1}} \\
& \dot{x}_{4}=\frac{x_{3}}{r_{c} C_{b}}-\frac{x_{4}}{C_{b}}\left(\frac{1}{r_{c}}+\frac{1}{r_{b}}\right)
\end{aligned}
$$

Where $x_{1}=v_{c 0}, x_{2}=i_{1}, x_{3}=v_{1}$ and $x_{4}=v_{2}$ are the state variables of the DC/DC converter. One notes $v_{1}$ and $v_{2}$ are respectively the voltage at the terminals of capacitor $\mathrm{C}_{1}$, and capacitor $\mathrm{C}_{\mathrm{b}}, i_{1}$ and $i_{p v}$ represent respectively the current circulate in the inductor $\mathrm{L}$, and the photovoltaic current. The switch position function is represented by the input control $\mu$ that takes the values in $[0,1]$. 
Table 2. Specifications of sliding mode control parameters

\begin{tabular}{|c|c|}
\hline Parameters name & Value \\
\hline $\mathrm{C}_{0}$ & $2000 \mu F$ \\
\hline $\mathrm{L}$ & $4.5 \mathrm{mH}$ \\
\hline Switching frequency & $20 \mathrm{KHz}$ \\
\hline $\mathrm{C}_{1}$ & $204 \mu F$ \\
\hline $\mathrm{r}_{\mathrm{c}}$ & $20 \mathrm{~m} \Omega$ \\
\hline $\mathrm{r}_{\mathrm{b}}$ & $10^{3} \Omega$ \\
\hline $\mathrm{C}_{\mathrm{b}}$ & $1470 \mathrm{~F}$ \\
\hline $\mathrm{R}$ & $1 \Omega$ \\
\hline
\end{tabular}

\section{Proposed control design}

\subsection{Control objective}

Maximum power point tracking (MPPT) is a technique that allows, whatever the irradiation, to extract the maximum power in order to maximize the energy produced by the photovoltaic panel under variable conditions and thus meet the energy requirements of the system.

\subsection{Voltage reference optimization}

In this part, we realized an optimizer, which is based on the power-voltage characteristic at the temperature $25^{\circ} \mathrm{C}$ and variable irradiation. This optimizer is represented in the figure below, it is used to calculate online the optimal voltage in such a way this voltage will be neighbourhood to the optimal voltage of the photovoltaic panel, and then the maximum power will be injected to the DC/DC converter input.

-Power Optimizer:

The following figure shows the Optimal power-voltage characteristic obtained from the polynomial interpolation of points $\left(\mathrm{v}_{\mathrm{pv} \_ \text {opt }}, \mathrm{P}_{\mathrm{pv} \_ \text {opt }}\right)$. Each one of these points is characterized by the optimal voltage $\mathrm{v}_{\text {pv_opt }}$ that will be transmit to the closed loop as a reference signal of the PV voltage.

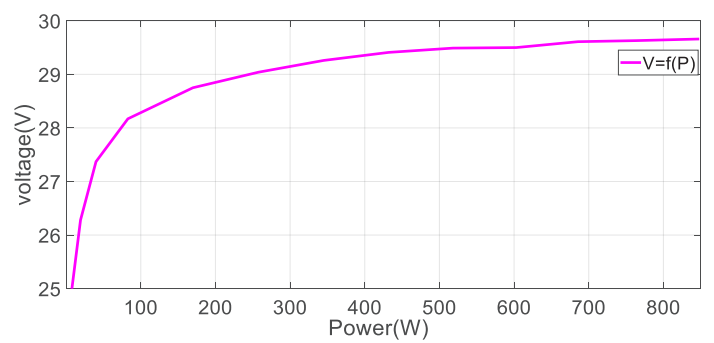

Fig. 4. The power-voltage (optimizer) curve obtained in $\mathrm{T}=25^{\circ} \mathrm{C}$ and variant irradiation

\subsection{Controller design}

In this section, a nonlinear approach namely the sliding mode control is used to manage the system to be near to the switching function. The sliding mode control applies a discontinuous control signal. This technique is based on two phases; the one allows determining the switch function with the aim that the movements of sliding respond to the design requirements and the other is used to select a control law.

The designated switching function for the power converters is represented as following [19-20]:

$$
S=\sum_{i=1}^{N} K_{i} e_{i}
$$

Where

$K_{i}$ : Sliding coefficients.

$e_{i}$ : State vectors errors.

The MPPT voltage error is:

$$
e_{1}=x_{1}-x_{1}^{*}
$$

Where

$x_{1}^{*}$ : Photovoltaic panel reference voltage Vpv_op

$x_{1}$ : Capacitor voltage.

The sliding surface is expressed as:

$$
S_{1}=\lambda_{1} e_{1}+K_{1} \int_{0}^{t} e_{1} d \tau
$$

Using (4.a) and derivate (7), the sliding surface is:

$$
\dot{S}_{1}=\lambda_{1}\left(\frac{i_{p v}}{C_{0}}-\mu \frac{x_{2}}{c_{0}}-\dot{x}_{1}^{*}\right)+K_{1} e_{1}
$$

If $\dot{S}\left(\mu_{e q}\right)=0$, the sliding mode exists. Therefore, the equivalent control is represented as follows:

$$
\mu_{e q}=\frac{1}{x_{2}}\left(i_{p v}+\frac{K_{1} C_{0}}{\lambda_{1}} e_{1}-C_{0} \dot{x}_{1}^{*}\right)
$$

The sliding mode control signal is defined as:

$$
\mu=\mu_{n}+\mu_{e q}
$$

Where $\mu_{e q}$ is the equivalent input control exploited by the sliding surface and $\mu_{n}$ is the robust switching input control, which is employed to carry back the operating point back to this sliding surface.

Consider the following Lyapunov equation $V_{1}=\frac{\mathrm{s}^{2}}{2}$, its derivate is:

$$
\dot{V}_{1}=S . \dot{S}
$$

Using (10) and (11), the Lyapunov function derivative is written as:

$$
\dot{V}_{1}=S\left(-\mu_{n} x_{2} \frac{\lambda_{1}}{C_{0}}\right)
$$

The nominal control choice $\mu_{n}=\beta_{1} \frac{C_{0}}{\lambda_{1}} \frac{1}{x_{2}} \operatorname{sign}(S)$ signified $\dot{V}_{1}=-\beta_{1}|S|$, where $\beta_{1}>0$.

$\beta_{1}$ is positive and $\frac{\lambda_{1}}{C_{0}}$ is all the time a positive value, it makes the adjustment of the controller dynamic. Therefore, the SMC is asymptotically stable.

By applying (10), the input control of MPPT mode is:

$$
\mu=\frac{1}{x_{2}}\left(i_{p v}+\frac{K_{1} C_{0}}{\lambda_{1}} e_{1}-C_{0} \dot{x}_{1}^{*}\right)+\beta_{1} \frac{C_{0}}{\lambda_{1}} \frac{1}{x_{2}} \operatorname{sign}(S)(13)
$$

\section{Proposition}

Consider the control system contains the subsystem (4) and the input control law (13), the resulting closed-loop system error $e_{1}=x_{1}-x_{1}^{*}$, converges asymptotically to zero, if the design parameters $K_{1}, \lambda_{1}$ and $\beta_{1}$ are real positive with $K_{1}>0, \lambda_{1}>0$ and $\beta_{1}>0$, the sliding mode 
surface is asymptotically stable. Consequently, the voltage $V_{p v}$ tends to its optimal value.

\section{Simulation results}

The experimental setup is described by Fig. 5 and the controller, developed in Section III, including the control law (13), will now be evaluated by simulation. The maximum output power of the photovoltaic panel used in this simulation is around to $848 \mathrm{~W}$. The controller of MPPT mode is used to generate the DCDC converter pulse. This converter adjusts the voltage and current variations of the circuit.

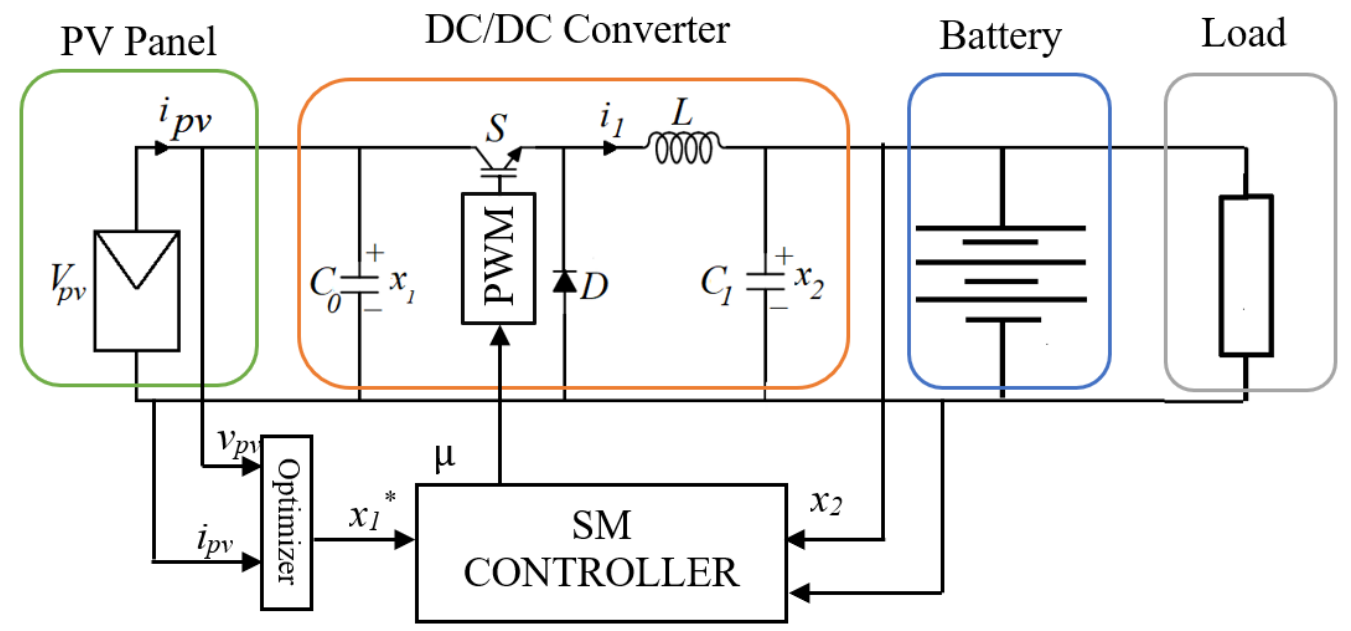

Fig. 5. Photovoltaic power system related to the control block diagram

This section contains the simulation results of the buck DC/DC converter controlled by sliding mode control, which is done MATLAB/ Simulink. The buck converter and sliding mode control parameters are listed on tables I and II.

Table 2. Specifications of sliding mode control parameters

\begin{tabular}{|c|c|}
\hline Parameters & Value \\
\hline $\mathrm{K}_{1}$ & $10^{3}$ \\
\hline$\lambda_{1}$ & 2 \\
\hline$\beta_{1}$ & 50 \\
\hline
\end{tabular}

\section{MPPT mode description}

During irradiation of $900 \mathrm{~W} / \mathrm{m}^{2}$ (figure (6.a)) the photovoltaic voltage reaches the optimum photovoltaic voltage (figure (6.c)); therefore, the error during this irradiation is approximated to zero. The state of charge; as mentioned in figure (6.f); increases proportionally, thus the battery in this state is on charging mode, and on the other hand, its voltage increases. At the instant $t=$ $1.6 s$, the load is connected to the system (figure (6.d) and the battery provides load to avoid the overload of battery which is completely charged. Consequently, the battery is in discharge mode, the power produces by the $\mathrm{PV}$ panel is greater than the power requirements by the system.

During irradiation of $100 \mathrm{~W} / \mathrm{m}^{2}$ (figure (6.a)), the load is continuously connected to the system. The PV power and optimal PV power reach $83 W$ (figure (6.b)), this power is less than the power required by the load which is almost $117 \mathrm{~W}$ (figure (6.g)) because the irradiation is very low. In this case, both the PV panel and battery provide the load. As noticed in figure (6.e), the current flowing in the battery decreased which is equal to almost zero. Consequently, the system did not work in normal conditions and both the PV panel and battery did not produce the requirement energy. It concluded under these conditions at a specific time, the system would be interrupted until the sunlight irradiation starts again.

\section{Conclusion}

In this paper, the problem of achieving MPPT of a standalone PV conversion system with battery storage energy is considered. A nonlinear controller is developed using sliding mode control approach for controlling the input voltage of a PWM-based DC-DC converter. The obtained MPPT controller consists of the optimizer voltage reference generator and the control laws (13). This designed approach is checked by simulations. This used technique provides robust performances to the considered system. The operating point is optimal and the extracted power is maximal without need to the atmospheric measurements.

\section{References}

1. C. Olalla, R. Leyva, A. El Aroudi, I. Queinnec, "Robust LQR control for PWM converters: An LMI approach," IEEE Trans. Ind. Electron, 56, 25482558, (2009).

2. A. Khaligh, J. Cao, Y. Lee, "A multiple-input DCDC converter topology," IEEE Trans. Power Electron, 24, 862 - 868, (2009). 
3. K. S. Kostov, J. Kyyra, and T. Suntio, "The input impedance of a Buck converter", European power Electronics Conf., (2003).

4. W. Chen, X. Wu, L. Yao, W. Jiang and R. Hu, "A Step-up Resonant Converter for Grid-Connected Renewable Energy Sources", IEEE Trans. Power Electron, 30, 3017 - 3029, (2015).

5. Robert W. Erickson, "DC-DC Power Converters", Wiley Encyclopedia of Electrical and Electronics Engineering, (2007).

6. S.V. Adhul, T. Ananthan, "FOPID Controller for Buck Converter", 3th. Int CoCoNet'19, 576 -582, (2020).

7. S. Ang A. Oliva, "Power-Switching Converters", Taylor and Francis Group, (2005).

8. F. Tahri, A. Tahri and S Flazi, "Efficient Digital Self Tuning Control of Step Down DC-DC Converter", 2èmes Journées d'Electrotechnique, de Maintenance et de Compatibilité, (2012).

9. B. Naik, A. Mehta,"Sliding mode controller with modified sliding function for DC-DC Buck Converter", ISA Transactions, 279 -287, (2017).

10. B.Labbe, B.Allard, X.Lin-Shi, D.Chesneau, "An integrated sliding-mode buck converter with switching frequency control for battery-powered applications", IEEE Trans. Power Electron, 28, 4318-4326, (2013).

11. M. Castilla, L. C. de Vicuna, M. Lopez, O. Lopez, and J. Matas, "On the design of sliding mode control schemes for quantum resonant converters", IEEE Trans. Power Electron., 15, 960-973, (2000).

12. H.Bayramoglu, H.Komurcugil, "Time-varying sliding-coefficient-based terminal sliding mode control methods for a class of fourth-order nonlinear systems", ISA Trans, 53, 1044-1053, (2014).

13. H. Sira-Ramirez, "On the generalized PI sliding mode control of DC-to-DC power converters: a tutorial”, Int. J. Control, 76, 1018-1033, (2003).

14. V. I. Utkin, H. C. Chang, "Sliding Mode Control on Electromechanical Systems", Math. Probl. Eng, 8, 451-473, (2002).

15. Z. Akpolat, M. Gökbulut, "Discrete Time Adaptive Reaching Law Speed Control of Electrical Drives", Electr. Eng, 85, 53-58, (2003).
16. İ. Eker, "Sliding Mode Control with PID Sliding Surface and Experimental Application to an Electromechanical Plant", ISA. Trans, 45, 109-118, (2006).

17. H.S. Ramirez, R.S. Ortigoza, "Control design techniques in power electronis devices", Power syst, 11-58, (2006).

18. V. Utkin, J. Gulder, and J. Shi, "Variable Structure Control Systems With Sliding Mode", 2nd ed. Boca Raton, FL, USA: CRC Press, (2009).

19. H. K. Khalil, nonlinear systems, 3 th ed, (2009).

20. A. El Fadili, F. Giri, A. El Magri, "Reference voltage optimizer for maximum power point tracking in triphase grid-connected photovoltaic systems", Int. J. Electr. Power Energy Syst, 60, 293-301, (2014).

21. A. Watil, A. El Magri, A. Raihani, R. Lajouad, F. Giri, "Multi-objective output feedback control strategy for a variable speed wind", Int. J. Electr. Power Energy Syst, 121, 106081, (2020).

22. Z.J. Andaloussi, A. Raihani, A. El Magri, O. Bouattane, "A new interconnection technique for PV panel cells using cubic topology". J. Eng. Res, 8(2), (2020).

23. R Lajouad, F Giri, FZ Chaoui, A El Fadili, A El Magri, "Output feedback control of wind energy conversion system involving a doubly fed induction generator", Asian J. Control, 21 (4), 2027-2037, (2019)

24. A El Fadili, S Boutahar, I Dhorhi, M Stitou, R Lajouad, A El Magri, "Reference Speed Optimizer Controller for Maximum Power Tracking in Wind Energy Conversion System Involving DFIG", REPS-GIE, 1-6, (2018).

25. El Fadili, A., Cuny, F., El Magri, A.,Janik, J.M., Chaoui, F.Z. "Backstepping Control of Photovoltaic-Grid Hybrid Power Feed Water Pump", IFAC-PapersOnLine, 50(1), pp. 65406545, (2017).

26. A. El Magri, F. Giri, A. El Fadili, L. Dugard, Adaptive Nonlinear Control of Wind Energy Conversion System with PMS Generator, IFAC Proceedings Volumes, 46(11), pp. 318-325, (2013). 


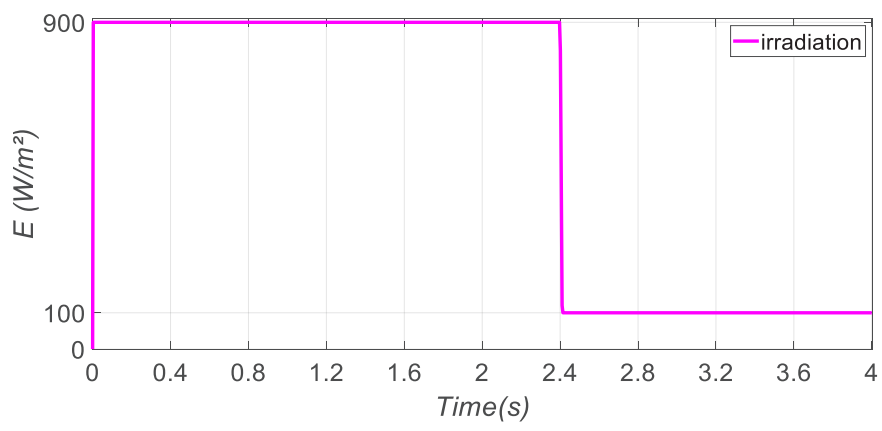

(A) IRRADIATION

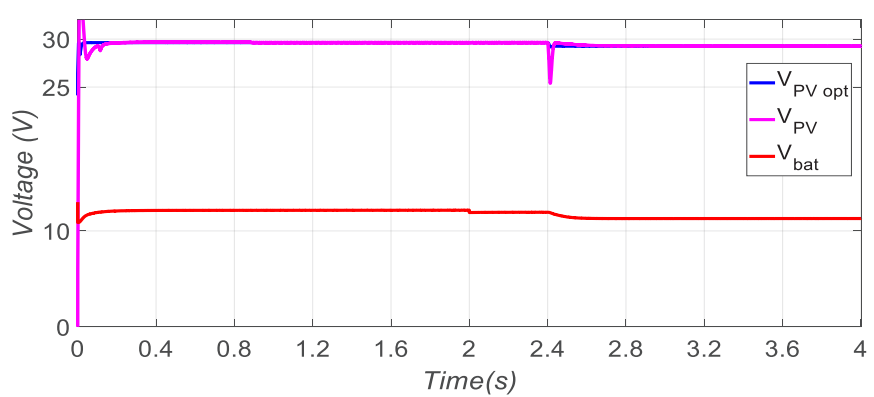

(C) LOAD, BATTERY AND PHOTOVOLTAIC VOLTAGES

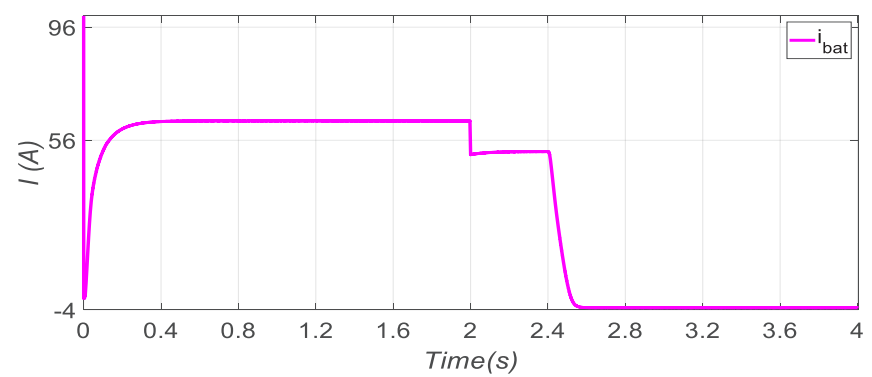

(E) BATTERY CURRENT

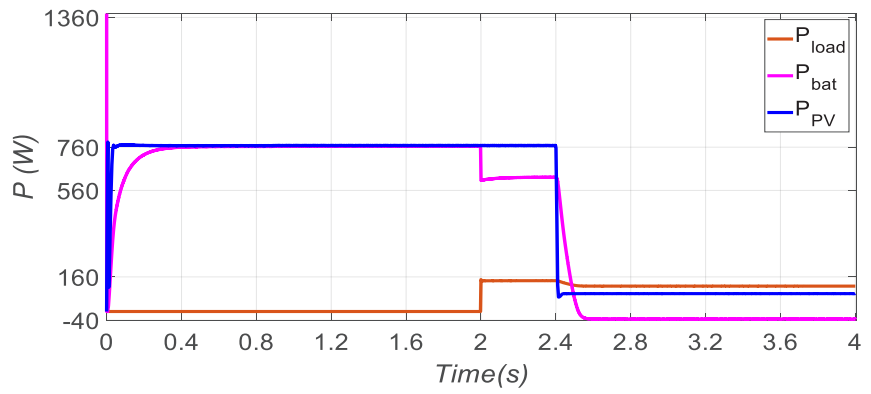

(G) LOAD, BATTERY AND PHOTOVOLTAIC POWERS

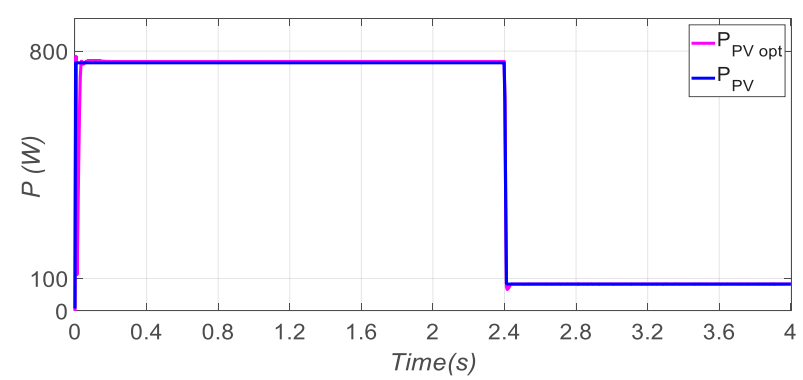

(B) PHOTOVOLTAIC POWER AND OPTIMAL PHOTOVOLTAIC POWER

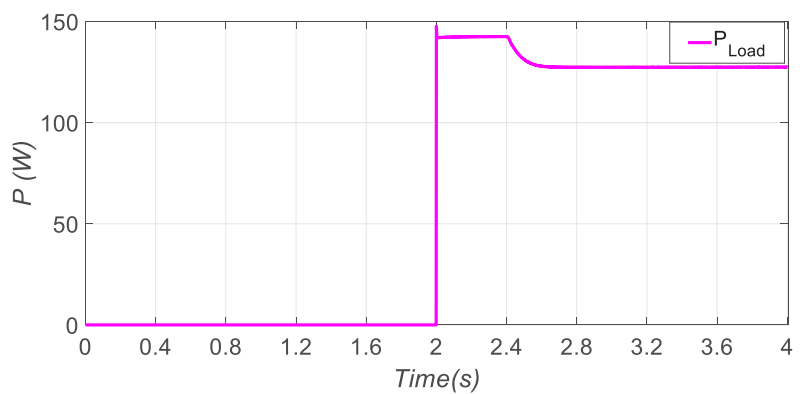

(D) LOAD POWER

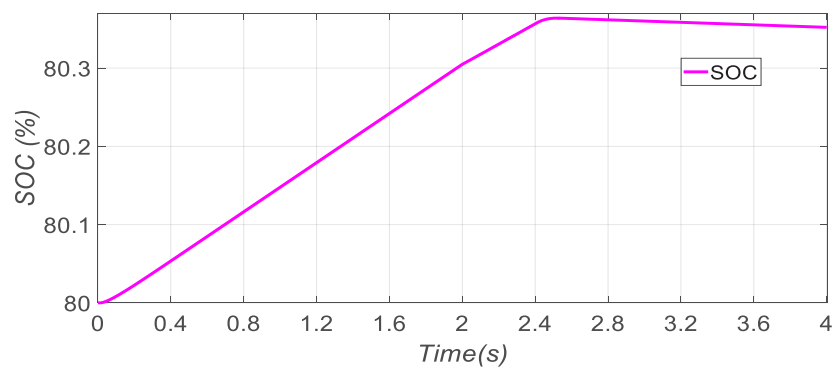

(F) STATE OF CHARGE

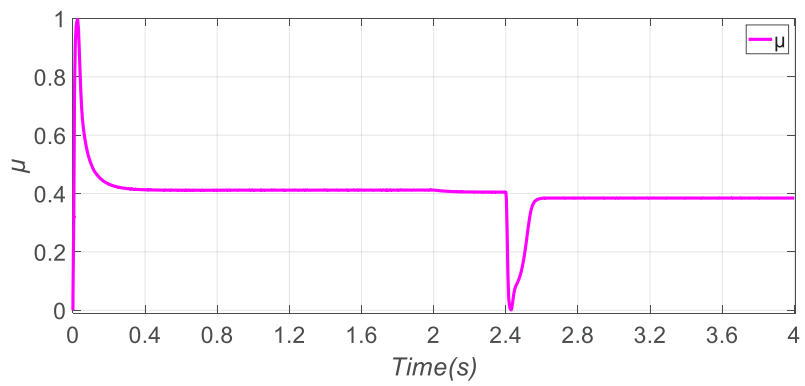

(H) INPUT CONTROL VOLTAGE

Fig. 6. Waveforms describing the system state during MPPT mode 